\title{
Real Time Elastography is an Easy Tool for Diagnosis of Liver Fibrosis in Non-Alcoholic Fatty Liver Disease
}

\author{
Badawy A. Abdulazizi ${ }^{*}$ Mohamed EL-Tantawy Ibrahim², Medhat A. Khalil'2, \\ Walid A. Abdel Halim ${ }^{3}$
}

\footnotetext{
${ }^{1}$ Hepatology, Gastroenterology and Infection Diseases Department, Faculty of Medicine, Benha University, Benha, Egypt ${ }^{2}$ Internal Medicine Department, Faculty of Medicine, Benha University, Benha, Egypt

${ }^{3}$ Clinical and Chemical Pathology Department, Faculty of Medicine, Benha University, Benha, Egypt Email: ^badawyabdelkhalek123@gmail.com, ^Badawi.omar@fmed.bu.edu.eg, tantawy_d@yahoo.com, medhatkhalil75@gmail.com,waleedabdellateef@gmail.com
}

How to cite this paper: Abdulaziz, B.A., Ibrahim, M.E.-T., Khalil, M.A. and Halim, W.A.A. (2020) Real Time Elastography is an Easy Tool for Diagnosis of Liver Fibrosis in Non-Alcoholic Fatty Liver Disease. Open Journal of Medical Imaging, 10, 110-124. https://doi.org/10.4236/ojmi.2020.102011

Received: May 12, 2020

Accepted: June 9, 2020

Published: June 12, 2020

Copyright $\odot 2020$ by author(s) and Scientific Research Publishing Inc. This work is licensed under the Creative Commons Attribution International License (CC BY 4.0).

http://creativecommons.org/licenses/by/4.0/

(c) (i) Open Access

\begin{abstract}
Background: Non-alcoholic fatty liver disease (NAFLD) has emerged a major challenge and become the leading indication for liver transplantation. We aimed to assess the applicability and performance of real-time elastography (RTE) in diagnosis of liver fibrosis in patients with NAFLD compared with NAFLD fibrosis score (NFS) and FIB-4 index. Patients and Methods: A prospective case-control study was conducted on 260 subjects attended Hepatology, Gastroenterology and Infectious diseases and Internal Medicine departments in Benha University Hospital from Marsh 20, 2018, to September 1, 2019 and divided into group I included 200 cases with NAFLD and group II included 60 healthy control subjects. Results: There was statistically significant increase in FIB-4 scores between two groups $(1.39 \pm 1.02$ and $-0.75 \pm 0.32$ respectively with $\mathrm{p}<0.001)$, also there was statistically significant increase in NAFLD fibrosis score mean \pm SD between two groups $(-1.74$ \pm 1.17 and $-2.75 \pm 0.91$ respectively with $\mathrm{p}<0.001$ ). Fibrosis stages in NAFLD patients significantly higher than in control group diagnosed by RTE $(\mathrm{P}=0.001)$. There was an agreement between RTE and FIB-4 index (93\%) and NAFLD fibrosis score (86\%). Diagnostic performance of RTE in advanced liver fibrosis $\geq \mathrm{F} 3$ was assessed in comparing with FIB-4 index show sensitivity 90\%, specificity 93.3\%, PPV 60\%, NPV 98.8\% and accuracy 93\% with AUC0.917 $(\mathrm{p}=0.001)$ and in comparing with NAFLD fibrosis score sensitivity $52.6 \%$, specificity $93.8 \%$, PPV $66.7 \%$, NPV $98.4 \%$ and accuracy $86 \%$ with AUC 0.732 $(\mathrm{p}=0.002)$. Conclusion: Real time elastography could be valuable in diagnosis of fibrosis in NAFLD especially in cases more than F3 score.
\end{abstract}




\section{Keywords}

Non-Alcoholic Fatty Liver Disease, Real Time Elastography, FIB-4 Index, NAFLD Fibrosis Score

\section{Introduction}

Non-alcoholic fatty liver disease (NAFLD) has emerged a major challenge because of its prevalence, difficulties in diagnosis, complex pathogenesis, and lack of approved therapies [1]. NAFLD ranges from simple steatosis without fibrosis to non-alcoholic steatohepatitis (NASH) with varying stages of fibrosis and NASH-related cirrhosis [2] [3]. Simple steatosis is thought to be a non-progressive condition. However, NASH is projected to be the main cause of liver transplantation by 2020 [4]. Meanwhile, NASH with advanced fibrosis is associated with increased risk of liver and cardiovascular-related mortality [2] [5]. Therefore, diagnosing advanced fibrosis in NAFLD patients is critical. The global prevalence of NAFLD diagnosed by imaging is around $25.24 \%$ the highest prevalence of NAFLD is reported from the Middle East (31.79\%) and South America (30.45\% [95\% CI, $22.74-39.440]$ ) and the lowest prevalence rate is reported from Africa (13.48\%) [6] liver biopsy has been the gold standard for diagnosis and staging of liver fibrosis, However, it cannot be used as a routine screening tool to detect or monitor fibrosis progression in NAFLD as there are many drawbacks of liver biopsy, including variable accessibility, high cost, sampling errors, and inaccuracy due to inter- and intra-observer variability of pathologic interpretations [7]. Therefore, the development of non-invasive assessments for fibrosis in patients with NAFLD has become essential in clinical practice.

Some non-invasive fibrosis scoring systems include the FIB-4 index (based on age, aspartate aminotransferase [AST], alanine aminotransferase [ALT] and platelet count) and NAFLD fibrosis score (NFS) have been develop by combining various serological parameters, which are easily and routinely obtained from patients [8] [9]. The NAFLD fibrosis score using variables (age, BMI, hyperglycemia, platelet count, albumin, and AST/ALT ratio) and is calculated using this formula $\left[-1.675+0.037 \times\right.$ age $($ years $)+0.094 \times \mathrm{BMI}\left(\mathrm{kg} / \mathrm{m}^{2}\right)+1.13 \times \mathrm{IFG} /$ diabetes $($ yes $=1$, no $=0)+0.99 \times$ AST $/$ ALT ratio $-0.013 \times$ platelet $\left(\times 10^{9} / \mathrm{l}\right)-0.66 \times$ albumin $(\mathrm{g} / \mathrm{dl})]$ NAFLD Score $<-1.455=$ F0 - F2 NAFLD FIB-4 $=-1.455-0.675$ $=$ indeterminate and NAFLD Score $>0.675=$ F3 - F4 [10].

FIB-4 index is based on platelet count, age, AST, and ALT that offers dual cut-off values (patients with score $<1.45$ are unlikely, whereas patients with score $>3.25$ are likely to have advanced fibrosis): Using this formula: (Age $\times$ AST) $/\{$ Platelets $\times$ [sqr (ALT)]\} [10]. Ultrasound is a safe, radiation-free, easily available, cost-effective tool of determining fatty infiltration of liver [11]. Real time elastography (RTE) has been reported to be useful for the prediction of fi- 
brosis in patients with non-alcoholic fatty liver disease with accuracy reaching 92\% [12]. The interest of transient elastography (FibroScan ${ }^{\circ}$; Echosens, Paris, France) has been demonstrated in meta-analysis studies to detect advanced fibrosis and early cirrhosis [13] [14]. Real time elastography has been found to have a good correlation with liver fibrosis stage determined by histopathologic examination of biopsy samples [12]. This study aims to assess the applicability and performance of real-time elastography (RTE) in diagnosis of liver fibrosis in patients with NAFLD compared with NAFLD fibrosis score (NFS) and FIB-4 index.

\section{Materials and Methods}

\subsection{Study Area and Period}

The study was conducted in Hepatology, Gastroenterology and Infectious diseases, Internal Medicine departments in Benha University Hospitals from Marsh 20, 2018, to September 1, 2019.

\subsection{Study Population}

This a prospective case-control study was conducted on 260 subjects and were divided into group I included 200 cases with NAFLD (diagnosed by abdominal ultrasonography with or without elevated liver enzymes) and group II included 60 healthy control subjects (normal liver in transabdominal ultrasonography and normal liver enzymes). Written informed consents were taken from patients after explaining all procedures and type of study.

\subsubsection{Inclusion Criteria}

1) Age above 18 Years.

2) Patients with NAFLD diagnosed by transabdominal ultrasonography.

\subsubsection{Exclusion Criteria}

Patients below the age of 18, patients with significant alcohol consumption, hepatitis $C$, hepatitis $B$, patients with symptoms or signs suggestive of haemochromatosis, Wilson's disease, alpha-one anti-trypsin deficiency, autoimmune hepatitis, history of intake of steatogenic medications, patients with decompensated cirrhosis, severe heart failure, severe renal failure or pregnancy were all excluded.

\subsection{Study Design}

A prospective case-control study was employed.

Full history and thorough clinical examination were done for all patients. The clinical/pathological data of the patients were recorded, including age, sex, history of steatogenic medications intake, alcohol intake, manifestaions of chronic liver diseases due to viral or other non-viral causes (ascites, LL oedema, jaundice, pruritus, kyser Fleisher ring by slit lamp examination, clubbing of fingers, signs of chest disease, signs of heart and renal failure). 


\subsection{Anthropometric Assessments}

Weight, height and body mass index (BMI) were measured for each patient. BMI formula uses weight (in $\mathrm{kg}$ ) and height (in meters) and expressed in $\mathrm{kg} / \mathrm{m}^{2}$ using this formula weight $(\mathrm{kg}) /[\text { height }(\mathrm{m})]^{2}$.

BMI results are interpreted as follows:

- BMI below 18.5 = Underweight;

- BMI $18.5-24.9=$ Normal weight;

- BMI 25.0 - 29.9 = Overweight;

- BMI 30.0 and above = Obese [15].

\subsection{Blood Collection and Sample Preparation}

Ten millilitres of blood was withdrawn from each subject. The complete blood count was estimated using a cell counter with a Cell Dyn machine. The estimation of the levels of serum creatinine and liver enzymes was performed using a kinetic method via an automated Dimension system. The serum levels of albumin, prothrombin concentration (PC), the international normalized ratio (INR) for prothrombin time. Fasting blood sugar and 2 hours post-prandial $(\mathrm{mg} / \mathrm{dL})$, $\mathrm{HbA}_{1} \mathrm{c}(\%)$, Viral markers including HBsAg by using $3^{\text {rd }}$ generation enzyme linked immunosorbent assay technique (ELISA) and Anti-HCV-Ab by using $3^{\text {rd }}$ generation enzyme linked immunosorbent assay technique (ELISA). Lipid profile includes total cholesterol ( $\mathrm{mg} / \mathrm{dl})$. Triglycerides $(\mathrm{mg} / \mathrm{dl})$, high density lipoproteins (HDL) (mg/dl) and Low density lipoprotein (LDL) (mg/dl).

\subsection{FIB-4 Index: Using This Formula}

$($ Age $\times$ AST $) /\{$ Platelets $\times[\operatorname{sqr}($ ALT $)]\}$.

FIB-4 Index $<1.45=\mathrm{f} 0-\mathrm{f} 1$.

FIB-4 Index $1.45-3.25=\mathrm{f} 2-\mathrm{f} 3$.

FIB-4 Index $>3.25=$ f4 [10].

\subsection{The NAFLD Fibrosis Score: Using This Formula}

$-1.675+0.037 \times$ age $($ years $)+0.094 \times$ BMI $\left(\mathrm{kg} / \mathrm{m}^{2}\right)+1.13 \times$ IFG/diabetes $($ yes $=$ 1 , no $=0)+0.99 \times$ AST/ALT ratio $-0.013 \times$ platelet $(\times 109 / 1)-0.66 \times$ albumin (g/dl).

NAFLD Score $<-1.455=$ F0 - F2.

NAFLD FIB- $4=-1.455-0.675=$ indeterminate score.

NAFLD Score $>0.675=$ F3 - F4 [10].

\subsection{Imaging}

1) Real time abdominal ultrasound was done by TOSHIBA-SSA-700A (Apilo 5)

Grading of steatosis revealed by ultrasound was done according to Singh et al., 2013 as follows:

Grade I: when the echogenicity is just increased more than the renal cortex. 
Grade II: when the echogenic liver obscures the echogenic walls of portal vein branches.

Grade III: when the echogenic liver obscures the diaphragmatic outline [11].

2) Real Time Elastography (RTE)

\subsection{Data Management and Statistical Analysis}

Data were precoded and entered in Microsoft Excel and and analyzed using SPSS version 16 soft ware (SPSS Inc, Chicago, ILL Company). Categorical data were presented as number and percentages while quantitative data were expressed as mean \pm standard deviation (S.D), median, IQR and range. Chi square test $\left(\mathrm{X}^{2}\right)$, or Fisher's exact test (FET) were used to analyze categorical variables. Coordinate of correlation was assessed by Cohen Kappa test was used to assess degree of agreement between 2 raters. Quantitative data were tested for normality using Shapiro-Wilks test, assuming normality at $\mathrm{P}>0.05$. Student " $t$ " test was used to analyze normally distributed variables among 2 independent groups. Non-parametric variables were analyzed using Man-Whitney U test. Difference among 3 independent means was analyzed using Kruskal Wallis test (KW) for non parametric variables. Significant KW tests was followed by post hoc multiple comparisons using Bonferroni test to detect the significant pairs. Spearman's correlation coefficient (rho) was used to assess correlations. ROC curve analysis was constructed to assess the performance of real time in prediction of fibrosis among patients group.

\section{Results}

Two hundred patients (group I) and 60 healthy subjects as control (group II) were allocated in this study in the period from Marsh, 2018, to September, 2019. the main demographic and laboratory variables of the included patients and control are presented in Table 1 which shows statistically significant differences among means of: DM $(\mathrm{P}<0.001)$, weight $\mathrm{P}<0.001)$, BMI $(\mathrm{P}<0.001)$, cholesterol $(\mathrm{P}<0.001)$, HDL $(\mathrm{P}<0.001)$, LDL $(\mathrm{P}<0.001)$, TG $(\mathrm{P}<0.001)$, AST $(\mathrm{P}<$ 0.001), ALT $(\mathrm{P}<0.001)$, T. bilirubin $(\mathrm{P}<0.001)$, S. albumin $(\mathrm{P}<0.001)$, WBCs $(\mathrm{P}<0.001)$, FIB-4 score $(\mathrm{P}<0.001)$ and NAFLD-fibrosis score $(\mathrm{P}<0.001)$ while other variables showed statistically insignificant differences. Also, Table 1 shows that there was statistical significant differences in FIB- 4 scores mean \pm SD between two groups $(1.39 \pm 1.02$ and $-0.75 \pm$ respectively with $\mathrm{p}<0.001)$, also there was statistical significant differences in NAFLD-FIBROSIS score mean \pm SD between two groups $(-1.74 \pm 1.17$ and $-2.75 \pm 0.91$ respectively with $\mathrm{p}<$ 0.001). Table 2 shows that advanced FIB-4 scores $(3-4)$ in group I (patients) more than in group II (control) (10\% and $0 \%$ respectively) while early FIB-4 scores (stage 0 - 1) were common in Group II ( $96.7 \%$ and $61 \%$ respectively). Table 3 shows that there were advanced NAFLD fibrosis scores (F3 - 4) in Group I (patients) more than in Group II (control) while NAFLD fibrosis score (stage 0 1) was common in Group II. Fatty liver was diagnosed by ultrasonography and 
represented as follow grade $1(48 \%)$, grade $2(24 \%)$ and grade $3(28 \%)$ while in Group II all subjects had normal liver. There was increase in grades of liver fibrosis by real time elastrography in Group I (patients) than in Group II (controls) and this was statistically significant $\mathrm{P}=0.001$ ). In Table $4,10 \%, 16 \%$ and $15 \%$ of NAFLD patients were categorized as having "significant fibrosis" (F3 \& F4) by FIB4-INDEX, NAFLD-FIBROSIS SCORE and RTE respectively ( $\mathrm{p}>$ 0.05).

Table 1. Demographic and laboratory data in between studied groups.

\begin{tabular}{|c|c|c|c|}
\hline Variable & $\begin{array}{l}\text { Group I } \\
\mathrm{N}=200\end{array}$ & $\begin{array}{c}\text { Group II } \\
\mathrm{N}=60\end{array}$ & $\mathbf{P}$ \\
\hline \multicolumn{4}{|l|}{ Age } \\
\hline$($ mean $\pm S D)$ & $47.1 \pm 11.6$ & $43.1 \pm 9.9$ & 0.086 \\
\hline \multicolumn{4}{|l|}{ Sex } \\
\hline Male (n, \%) & $110(55 \%)$ & $30(50 \%)$ & 0.63 \\
\hline Female (n, \%) & $90(45 \%)$ & $30(15 \%)$ & \\
\hline \multicolumn{4}{|l|}{ Weight (kg) } \\
\hline$($ mean $\pm S D)$ & $94.09 \pm 17.0$ & $75.0 \pm 13.22$ & $<0.001$ (HS) \\
\hline \multicolumn{4}{|l|}{ Height $(\mathrm{cm})$} \\
\hline$($ mean $\pm S D)$ & $167.6 \pm 6.16$ & $169.1 \pm 6.72$ & 0.25 (NS) \\
\hline \multicolumn{4}{|l|}{ BMI } \\
\hline$($ mean $\pm \mathrm{SD}), \mathrm{kg} / \mathrm{m}^{2}$ & $33.4 \pm 5.34$ & $26.1 \pm 3.62$ & $<0.001(\mathrm{HS})$ \\
\hline Diabetes mellitus (n, \%) & $142(71 \%)$ & $0(0 \%)$ & 0.001 (HS) \\
\hline Cholesterol (mean \pm SD) & $236.0 \pm 17.7$ & $123.1 \pm 16.6$ & $<0.001$ (HS) \\
\hline HDL (mean CSD) & $58.5 \pm 8.33$ & $86.2 \pm 9.44$ & $<0.001(\mathrm{HS})$ \\
\hline LDL $($ mean \pm SD $)$ & $139.5 \pm 9.71$ & $82.1 \pm 11.72$ & $<0.001$ (HS) \\
\hline $\operatorname{AST}($ mean $\pm S D, U / L)$ & $35.8 \pm 29.4$ & $20.0 \pm 5.8$ & $<0.001$ (HS) \\
\hline $\mathrm{ALT}($ mean $\pm \mathrm{SD}, \mathrm{U} / \mathrm{L})$ & $39.7 \pm 29.8$ & $19.1 \pm 7.3$ & $<0.001$ (HS) \\
\hline T. bilirubin $($ mean $\pm \mathrm{SD}, \mathrm{mg} / \mathrm{dl})$ & $0.72 \pm 0.17$ & $0.86 \pm 0.09$ & $<0.001$ (HS) \\
\hline S. albumin $($ mean $\pm \mathrm{SD}, \mathrm{g} / \mathrm{l})$ & $4.15 \pm 0.36$ & $4.55 \pm 0.43$ & $<0.001$ (HS) \\
\hline INR & $1.00 \pm 0.01$ & $1.00 \pm 0.00$ & 1.0 (NS) \\
\hline S. creatinine $(\mathrm{mg} / \mathrm{dl})$ & $0.90 \pm 0.15$ & $0.91 \pm 0.07$ & $0.63(\mathrm{NS})$ \\
\hline $\mathrm{HB}(\mathrm{gm} / \mathrm{dl})$ & $13.1 \pm 1.85$ & $12.9 \pm 1.52$ & 0.48 (NS) \\
\hline WBCs $(\mathrm{cm})$ & $7171.4 \pm 2043.91$ & $6302.5 \pm 1283.16$ & $0.38(S)$ \\
\hline PLTs $(\mathrm{cm})$ & $241.1 \pm 74.77$ & $241.9 \pm 50.90$ & $0.76(\mathrm{NS})$ \\
\hline FIB-4 score points (mean \pm SD) & $1.39 \pm 1.02$ & $-0.75 \pm 0.32$ & $<0.001$ (HS) \\
\hline NAFLD score points (mean \pm SD) & $-1.74 \pm 1.17$ & $-2.75 \pm 0.91$ & $<0.001$ (HS) \\
\hline
\end{tabular}

Table 2. FIB-4 score between the studied groups.

\begin{tabular}{cccc}
\hline FIB-4 score & Group I & Group II & total \\
\hline Stage $0-1(\mathrm{n}, \%)$ & $122(61 \%)$ & $\mathbf{N}=60$ & $180(69.2 \%)$ \\
Stage $2-3(\mathrm{n}, \%)$ & $58(29 \%)$ & $58(96.7 \%)$ & $60(23.1 \%)$ \\
Stage 3 $-4(\mathrm{n}, \%)$ & $20(10 \%)$ & $2(3.3 \%)$ & $20(7.75)$ \\
Total $(\mathrm{n}, \%)$ & $200(100 \%)$ & $1(0.0 \%)$ & $260(100 \%)$ \\
\hline
\end{tabular}


Table 3. NAFLD fibrosis score in groups of the study.

\begin{tabular}{cccc}
\hline NAFLD fibrosis score & $\begin{array}{c}\text { Group I } \\
(\mathbf{n}=\mathbf{2 0 0})\end{array}$ & $\begin{array}{c}\text { Group II } \\
(\mathbf{n}=60)\end{array}$ & Total \\
\hline F0 - F2 (n, \%) & $96(48 \%)$ & $58(96.7 \%)$ & $154(59.2 \%)$ \\
Indeterminant (n, \%) & $72(36 \%)$ & $2(3.3 \%)$ & $74(27.7 \%)$ \\
F3 - 4 (n, \%) & $32(16 \%)$ & $0(0 \%)$ & $32(12.3 \%)$ \\
\hline
\end{tabular}

Table 4. Frequency of significant fibrosis (F3 \& F4) among patients with NAFLD according to FIB4-INDEX, NAFLD-FIBROSIS score and RTE.

\begin{tabular}{lllll}
\hline & $\begin{array}{l}\text { Number of patients } \\
\text { with No significant } \\
\text { fibrosis }\end{array}$ & $\begin{array}{l}\text { Number of patients } \\
\text { With significant } \\
\text { fibrosis }\end{array}$ & $\mathrm{X}^{2}$ & p-value \\
\hline FIB4-INDEX & 180 & 20 & 1.7516 & 0.416533 \\
NAFLD-FIBROSIS score & 168 & 32 & & \\
RTE & 170 & 30 & & \\
\hline
\end{tabular}

The chi-square statistic is 1.7516 . The $\mathrm{p}$-value is 0.416533 . The result is not significant at $\mathrm{p}<0.05$.

The degree of agreement between FIB-4 score and NAFLD-FIBROSIS score in diagnosis of liver fibrosis was (89\%) and presented statistically significant as Kappa test $=0.563$ and $(P=0.001)($ Table 5$)$. The degree of agreement between FIB-4 score and real time elastrography in diagnosis of liver fibrosis was (93\%) and presented statistically significant as Kappa test $=0.682$ and $(\mathrm{P}=0.001)$ (Table 6).

The degree of agreement between real time elastography and NAFLDFIBROSIS score results in diagnosis of liver fibrosis in NAFLD was (86\%) and presented statistically significant as Kappa test $=0.505$ and $(\mathrm{P}=0.001)$ (Table 7)

In Table 6 and Table 7, the degree of agreement between FIB4-INDEX and NAFLD-FIBROSIS score, on the one hand, and real time elastography (RTE) on the other hand, were $93 \%$ and $86 \%$ respectively (Kappa test $=0.682 \& 0.505 ; \mathrm{P}<$ $0.001)$.

The ROC analysis of real time elastrography (talking FIB-4 score as a gold standard) in advanced degree of liver fibrosis $\geq$ F3 which was statistically highly significant $(\mathrm{P}=0.001)$, sensitivity $90 \%$, specificity $93.3 \%$, accuracy $93 \%$ and AUC 0.917 (Figure 1).

ROC curve analysis of real time elastrography (talking NAFLD-fibrosis score as a gold standard) in advanced degree of liver fibrosis $\geq$ F3 which was statistically significant $(\mathrm{P}=0.002)$ with sensitivity $52.6 \%$, specificity $93.8 \%$, accuracy $86 \%$ and AUC 0.732 (Figure 2). In advanced liver fibrosis $\geq$ F3 by real time elastography there is a good relation between ultrasound grading of fatty liver and liver fibrosis by elastrography $(\mathrm{P}=0.001)$ while in lower scores $<\mathrm{F} 3$ this relation was not present in Table 8. In advanced FIB-4 score $(\geq F 3)$ there is a good positive relation between grading of fatty liver by ultrasonography and FIB-4 score $(\mathrm{P}=0.001)$ while in lower FIB-4 score $(<\mathrm{F} 3)$ this relation was not present in Table 9. In advanced NAFLD-fibrosis score $(\geq F 3)$ there is a good positive re- 
lation between grading of fatty liver by ultrasound and NAFLD fibrosis score ( $\mathrm{P}$ $=0.001)$ while in lower NAFLD-fibrosis score $(<\mathrm{F} 3)$ this correlation was not present in Table 10.

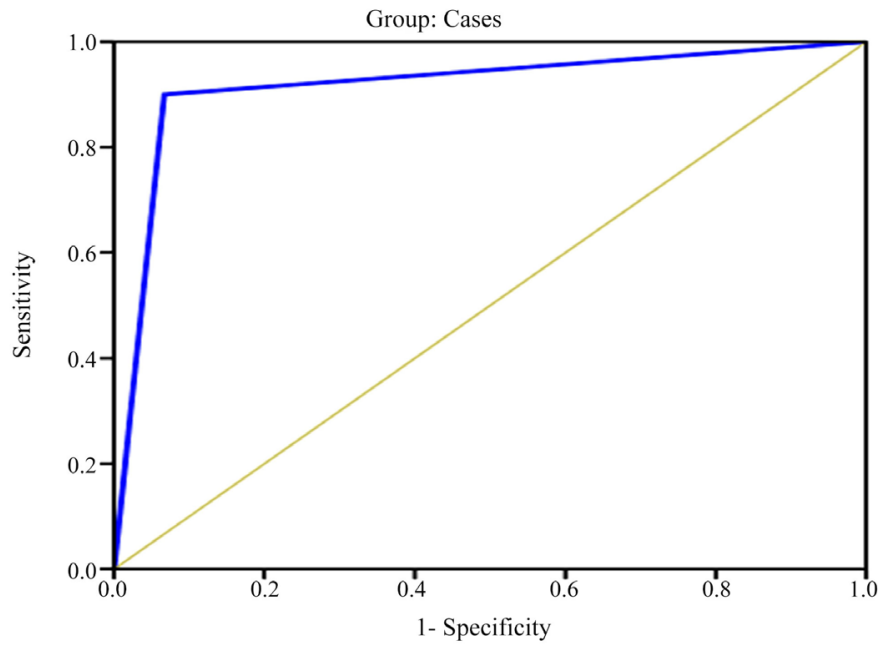

Figure 1. ROC curve for the performance of real time elastography in prediction of $\mathrm{F} 3$ or more (taking FIB-4 as a standard).

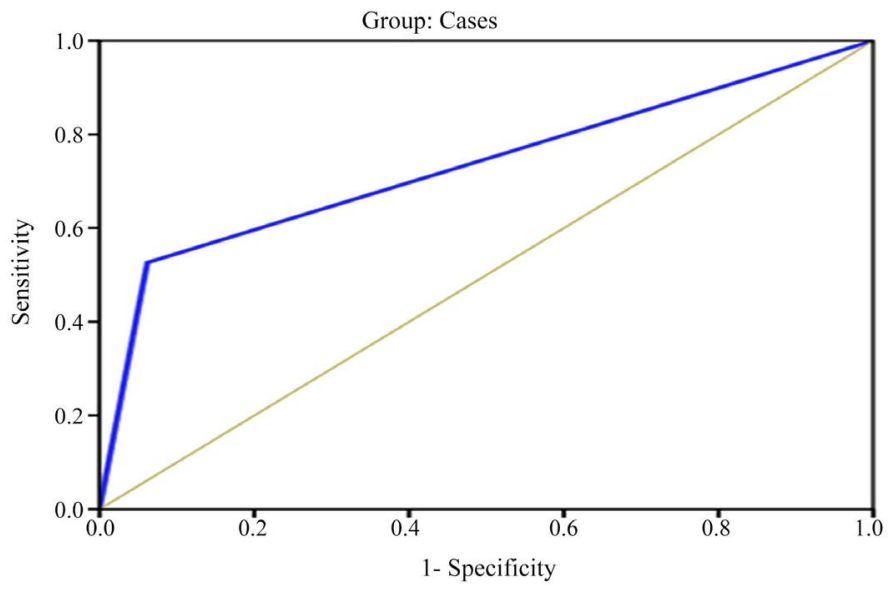

Figure 2. ROC curve for the performance of real time elastography in prediction of F3 or more (taking NAFLD as a standard).

Table 5. Degree of agreement between FIB-4 and NAFLD-fibrosis score results in diagnosis the degree of liver fibrosis.

\begin{tabular}{|c|c|c|c|c|}
\hline \multirow{2}{*}{\multicolumn{2}{|c|}{ FIB-4 index }} & \multicolumn{2}{|c|}{ NAFLD fibrosis score } & \multirow{2}{*}{-Total } \\
\hline & & \multirow{2}{*}{$<\mathrm{F} 3$} & \multirow{2}{*}{$\geq \mathrm{F} 3$} & \\
\hline \multicolumn{3}{|l|}{ FIB-4 } & & \\
\hline \multirow[t]{2}{*}{$<\mathrm{F} 3$} & count & 160 & 20 & 180 \\
\hline & $\%$ within NAFLD & $98.8 \%$ & $52.6 \%$ & $90.0 \%$ \\
\hline \multirow[t]{2}{*}{$\geq \mathrm{F} 3$} & count & 2 & 18 & 20 \\
\hline & $\%$ within NAFLD & $1.2 \%$ & $47.4 \%$ & $10.0 \%$ \\
\hline \multirow[t]{2}{*}{ Total } & count & 162 & 38 & 200 \\
\hline & $\%$ within NAFLD & $100.0 \%$ & $100.0 \%$ & $100.0 \%$ \\
\hline
\end{tabular}

Kappa test $=0.563 ; \mathrm{P}<0.001(\mathrm{HS}) ;$ Degree of agreement $=89 \%$. 
Table 6. Degree of agreement between real time elastography and FIB-4 score results in diagnosis of liver fibrosis in NAFLD.

\begin{tabular}{|c|c|c|c|}
\hline \multirow{2}{*}{$\begin{array}{l}\text { Real time } \\
\text { Elastography }\end{array}$} & \multicolumn{2}{|c|}{ FIB-4 Score } & \multirow{2}{*}{-Total } \\
\hline & $<\mathrm{F} 3$ & $\geq \mathrm{F} 3$ & \\
\hline \multicolumn{4}{|l|}{ FIB-4 } \\
\hline$<$ F3 count & 168 & 2 & 170 \\
\hline$\%$ within NAFLD & $84 \%$ & $1 \%$ & $85 \%$ \\
\hline$\geq \mathrm{F} 3 \quad$ count & 12 & 18 & 30 \\
\hline$\%$ within NAFLD & $6 \%$ & $9 \%$ & $15 \%$ \\
\hline Total count & 180 & 20 & 200 \\
\hline$\%$ within NAFLD & $90 \%$ & $10 \%$ & $100.0 \%$ \\
\hline
\end{tabular}

Kappa test $=0.682 ; \mathrm{P}<0.001(\mathrm{HS}) ;$ Degree of agreement $=93 \%$.

Table 7. Degree of agreement between real time elastography and NAFLD-fibrosis score results in diagnosis of liver fibrosis in NAFLD.

\begin{tabular}{|c|c|c|c|c|}
\hline \multirow{2}{*}{\multicolumn{2}{|c|}{ Real time Elastography }} & \multicolumn{3}{|c|}{ NAFLD Fibrosis score } \\
\hline & & \multirow{2}{*}{$\begin{array}{l}<\mathrm{F} 3 \\
152\end{array}$} & \multirow{2}{*}{$\begin{array}{l}\geq \mathrm{F} 3 \\
18\end{array}$} & \multirow{2}{*}{$\begin{array}{l}\text {-Total } \\
170\end{array}$} \\
\hline$<$ F3 & count & & & \\
\hline & \% within FIB-4 & $76 \%$ & $9 \%$ & $85 \%$ \\
\hline \multirow[t]{2}{*}{$\geq \mathrm{F} 3$} & count & 10 & 20 & 30 \\
\hline & \% within FIB-4 & $5 \%$ & $10 \%$ & $15 \%$ \\
\hline \multirow[t]{2}{*}{ Total } & count & 162 & 38 & 200 \\
\hline & \% within FIB-4 & $81 \%$ & $19 \%$ & $100 \%$ \\
\hline
\end{tabular}

Kappa test $=0.505 ; \mathrm{P}<0.001(\mathrm{HS}) ;$ Degree of agreement $=86 \%$.

Table 8. Relation between grades of fatty liver screened by ultrasound and fibrosis stages diagnosed by real time elastography.

\begin{tabular}{|c|c|c|c|c|c|}
\hline \multirow{2}{*}{ FIB-4 } & & \multicolumn{3}{|c|}{ Abdominal ultrasonography (US) } & \multirow{2}{*}{ Total } \\
\hline & & \multicolumn{2}{|c|}{ Grade 1 fatty liver Grade 2 fatty liver } & Grade 3 fatty liver & \\
\hline \multirow[t]{2}{*}{$<\mathrm{F} 3$} & count & 96 & 46 & 28 & 170 \\
\hline & $\%$ within US & $48 \%$ & $95.8 \%$ & $50.0 \%$ & $85.0 \%$ \\
\hline \multirow[t]{2}{*}{$\geq$ F3 } & count & 0 & 2 & 28 & 30 \\
\hline & \% within US & $0.0 \%$ & $4.2 \%$ & $50.0 \%$ & $15.0 \%$ \\
\hline \multirow[t]{2}{*}{ Total } & count & 96 & 48 & 56 & 200 \\
\hline & \% within US & $48 \%$ & $24 \%$ & $28 \%$ & $100.0 \%$ \\
\hline
\end{tabular}

FET $=43.7, \mathrm{P}<0.001(\mathrm{HS})$.

Table 9. Relation between grades of fatty liver screened by abdominal ultrasonography and fibrosis stages diagnosed by FIB-4 score.

\begin{tabular}{llllll}
\hline \multirow{2}{*}{ FIB-4 } & \multicolumn{5}{c}{ Abdominal ultrasonography (US) } \\
\cline { 3 - 6 } \\
\cline { 3 - 6 } & & Grade 1 fatty liver & Grade 2 fatty liver & Grade 3 fatty liver \\
\hline$<$ F3 & count & 94 & 46 & 40 & 180 \\
& \% within US & $47 \%$ & $23 \%$ & $20 \%$ & $90 \%$ \\
$\geq$ F3 & count & 2 & 2 & 16 & 20 \\
& \% within US & $1 \%$ & $1 \%$ & $8 \%$ & $10.0 \%$ \\
Total & count & 96 & 48 & 56 & 200 \\
& \% within US & $48 \%$ & $24 \%$ & $28 \%$ & $100.0 \%$ \\
\hline
\end{tabular}


Table 10. Relation between grades of fatty liver screened by abdominal ultrasonography and fibrosis stages diagnosed by NAFLD fibrosis score.

\begin{tabular}{lllllll}
\hline \multirow{2}{*}{ NAFLD } & \multicolumn{5}{c}{ Abdominal ultrasonography (US) } & Total \\
\cline { 3 - 6 } & & Grade & 1 fatty liver & Grade 2 fatty liver & Grade 3 fatty liver & \\
\hline <F3 & count & 94 & 38 & 30 & 162 \\
& $\%$ within US & $47 \%$ & $19 \%$ & $15 \%$ & $81.0 \%$ \\
$\geq$ F3 & count & 2 & 10 & 26 & 38 \\
& $\%$ within US & $1 \%$ & $5 \%$ & $13 \%$ & $19.0 \%$ \\
\multirow{2}{*}{ Total } & count & 96 & 48 & 56 & 200 \\
& $\%$ within US & $48 \%$ & $24 \%$ & $28 \%$ & $100.0 \%$ \\
\hline
\end{tabular}

$\mathrm{FET}=23.02, \mathrm{P}<0.001(\mathrm{HS})$.

\section{Discussion}

For defining non-alcoholic fatty liver disease "NAFLD" there must be evidence of hepatic steatosis (HS), either by imaging or histology, and lack of secondary causes of hepatic fat accumulation such as significant alcohol consumption and long-term use of a steatogenic medication [16].

The overall global prevalence of NAFLD diagnosed by imaging is around $25.24 \%$ and the highest prevalence of NAFLD is reported from Middle East $31.79 \%[6]$.

In Egypt, the prevalence was 14.9 in diabetes, $70 \%$ in obesity and $7.4 \%$ in metabolic syndrome, while the prevalence of NAFLD diagnosed by ultrasound in obese children and adults was about $65.3 \%$ and $62.7 \%$ respectively [17].

Patients with NAFLD are at higher risk for adverse outcomes such as cirrhosis and liver-related mortality [18].

Liver biopsy is the gold standard for diagnosis and staging of liver fibrosis but there are many drawbacks of liver biopsy, including invasiveness, variable accessibility, high cost, sampling errors, and inaccuracy due to inter- and intra-observer variability of pathologic interpretations [10].

Imaging and biochemical tests such as (NAFLD-fibrosis score and FIB-4 Index) these non-invasive methods commonly used in the diagnosis of liver fibrosis in NAFLD to overcome the disadvantages of liver biopsy [10].

Real time elastography has been reported to be useful for the prediction of fibrosis in patients with non-alcoholic fatty liver disease with accuracy reaching 92\% and have a good correlation with liver fibrosis stage determined by histopathologic examination of biopsy samples [12]. The aim of this study was to assess the applicability and performance of real-time elastography for diagnosis of liver fibrosis in patients with non-alcoholic fatty liver disease (NAFLD) compared with NAFLD-fibrosis score and FIB-4 Index.

Patients and controls are age and sex matched. This eliminates confounding factors and validating further comparison.

Significant fibrosis $(\geq \mathrm{F} 3)$ was detected in $10 \%$ of patients by FIB- 4 and in $16 \%$ by NAFLD Fibrosis Score. This discrepancy indicated that NAFLD Fibrosis Score is probably more sensitive in the detection of significant fibrosis. However, 
it also indicates the need for other more reliable non-invasive methods for the detection of significant fibrosis. Significant fibrosis (F3 and F4) was detected in $15 \%$ of patients by RTE.

Also, there was another limitation of the NAFLD Fibrosis Score. 36\% of cases had "indeterminate" score; i.e. more than a third of all cases could not be categorized by this test, which further emphasizes the need for using more than one test to monitor the patients with NAFLD for fibrosis. RTE has no indeterminate zone and can, as such, replace other non-invasive methods for the assessment and monitoring of liver fibrosis.

In the current study, as much as $36.6 \%$ of healthy controls had F1 or F2 fibrosis by RTE. This finding indicates that clinical methods are not sufficient by themselves in excluding subtle liver pathology.

The present study revealed that in advanced liver fibrosis $(\geq \mathrm{F} 3)$ diagnosed by real time elastrography, Fib-4 index and NAFLD fibrosis score, there was a good relation between ultrasound grading of fatty liver and advanced fibrosis. This finding agrees with Mustapic 2018 and his colleagues who concluded that increase the grade of fatty liver by ultrasound associated with increase the degree of liver fibrosis [19]. FIB-4 INDEX and NAFLD-FIBROSIS SCORE are two time-honored non-invasive methods for estimating and monitoring of significant liver fibrosis in patients with NAFLD [10]. In the current study, there was an agreement between FIB- 4 and NAFLD fibrosis score by $89 \%$ in diagnosis of liver fibrosis in NAFLD and that was statistically significant $(p>0.001)$ this result is matched with McPherson and his colleagues who reported that The NAFLD fibrosis score and FIB-4 scores have similar accuracy for advanced fibrosis ( $p>0.001$ ) [20]. When correlating RTE, a recently introduced technique, with FIB4 INDEX and NAFLD-FIBROSIS SCORE, the degree of agreement reached $93 \%$ and $86 \%$ respectively $(\mathrm{p}<0.001)$. Accordingly, RTE agreed with the two universally accepted time-honored indices more than the latter two agreed to each other. That also reported by Rashed and his colleagues who stated that there is an agreement between FIB-4 and real time elastrography reached 90\% with $\mathrm{p}<0.001$ [21].

As a diagnostic method for significant fibrosis (F3 and F4), RTE had a sensitivity of $90 \%$ when FIB4 INDEX was taken as a gold standard (Figure 1), and $52.6 \%$ when NAFLD-FIBROSIS score was taken as a gold standard (Figure 2). In both cases, we are still far from finding the optimally ulmost diagnostic tool. However, it is definitely clear that the sensitivity of RTE is more closely correlated to FIB4-INDEX than NAFLD-FIBROSIS score. The NAFLD-FIBROSIS SCORE formula incorporates more parameters pertinent to the metabolic syndrome than the FIB4 INDEX. However, this might provide a higher sensitivity at the expense of specificity.

The specificity of RTE in diagnosis of significant fibrosis was $93.3 \%$ and $93.8 \%$ when FIB4-INDEX and NAFLD-FIBROSIS score were taken as gold standards respectively (Figure 1 \& Figure 2). The accuracy and the AUC values of RTE were $93 \%$ and 0.917 when FIB4-INDEX was taken as a reference standard 
(Figure 1). When NAFLD-FIBROSIS SCORE was taken as reference, the accuracy and AUC value of RTE were $86 \%$ and 0.732 respectively (Figure 2). Overall, RTE proved to as equally reliable as FIB4-INDEX and NAFLD-FIBROSIS score. However, it still has the added advantage of being immediately available for the patient and the physician during an office visit. This is important in the management of NAFLD patients which require repeated and frequent clinical interviews to monitor progress of a condition in which life style modifications are the most important part of treatment. So The present study showed that real time elastrography is a reliable, non-invasive and cost-effective method in diagnosis advanced liver fibrosis in NAFLD which agrees with Ochi et al., and Kanamoto et al., [22] and] [23]. Hashemi et al., stated that RTE is an easy method to evaluate liver fibrosis, noninvasive, needing short time to obtain results appreciated by patients [24]. Di and his colleagues also reported real time elastrography to be useful for early diagnosis and staging of liver fibrosis in NAFLD [25]. Some limitations of our study warrant to be mentioned. Diagnosis of NAFLD patients and liver fibrosis in our study were not histologically diagnosed by biopsy (which is the gold standard) however it is invasive and subjected to inter and intra observer variations and associated with complications so we try to avoid it by evaluating other non-invasive methods. In addition, this was not a population-based study covering a wide geographic area or a large number of patients. So our results need to be furtherly evaluated for validation on larger cohorts.

\section{Conclusion}

From our study, we can conclude that real time elastography can be beneficial in diagnosis and monitoring of fibrosis in non-alcoholic fatty liver disease especially in cases more than F3 score. I also suggest proposing some research that could be conducted in the future to further test some of these ideas.

\section{Acknowledgements}

The authors would like to thank the staff of Hepatology, Gastroenterology and Infectious Diseases Department in Benha University Hospital.

\section{Ethics Approval and Consent}

The Benha University Hospital Ethics Committee approved the study. All patients enrolled for the validation of this study gave a written informed consent.

\section{Conflicts of Interest}

The authors declare no conflicts of interest regarding the publication of this paper.

\section{References}

[1] Rinella, M.E. (2015) Nonalcoholic Fatty Liver Disease: A Systematic Review. JAMA, 313, 2263-2273. https://doi.org/10.1001/jama.2015.5370 
[2] Kim, D., Kim, W.R., Kim, H.J., et al. (2013) Association between Noninvasive Fibrosis Markers and Mortality among Adults with Nonalcoholic Fatty Liver Disease in the United States. Hepatology, 57, 1357-1365. https://doi.org/10.1002/hep.26156

[3] Farrell, G.C. and Larter, C.Z. (2006) Nonalcoholic Fatty Liver Disease: From Steatosis to Cirrhosis. Hepatology, 43, S99-S112. https://doi.org/10.1002/hep.20973

[4] Charlton, M. (2004) Nonalcoholic Fatty Liver Disease: A Review of Current Understanding and Future Impact. Clinical Gastroenterology and Hepatology, 2, 1048-1058. https://doi.org/10.1016/S1542-3565(04)00440-9

[5] Sesti, G., Sciacqua, A., Fiorentino, T.V., et al. (2014) Association between Noninvasive Fibrosis Markers and Cardio-Vascular Organ Damage among Adults with $\mathrm{He}$ patic Steatosis. PLoS ONE, 9, e104941. https://doi.org/10.1371/journal.pone.0104941

[6] Younossi, Z.M., Koenig, A.B., Abdelatif, D., Fazel, Y., Henry, L. and Wymer, M. (2016) Global Epidemiology of Nonalcoholic Fatty Liver Disease-Meta-Analytic Assessment of Prevalence, Incidence, and Outcomes. Hepatology, 64, 73-84. https://doi.org/10.1002/hep.28431

[7] Nalbantoqlu, I.L. and Brunt, E.M. (2014) Role of Liver Biopsy in Nonalcoholic Fatty Liver Disease. World Journal of Gastroenterology, 20, 9026-9037.

[8] Sterling, R.K., Lissen, E., Clumeck, N., Sola, R., Correa, M.C., Montaner, J., Sulkowski, M., Torriani, F.J., Dieterich, D.T., Thomas, D.L., Messinger, D. and Nelson, M. (2006) Development of a Simple Noninvasive Index to Predict Significant Fibrosis in Patients with HIV/HCV Coinfection. Hepatology, 43, 1317-1325.

https://doi.org/10.1002/hep.21178

[9] Williams, A.L. and Hoofnaqle, J.H. (1998) Ratio of Serum Aspartate to Alanine Aminotransferase in Chronic Hepatitis. Relationship to Cirrhosis. Gastroenterology, 95, 734-739. https://doi.org/10.1016/S0016-5085(88)80022-2

[10] Kaswala, D., Lai, M. and Afdhal, N. (2016) Fibrosis Assessment in Non Alcoholic Fatty Liver Disease (NAFLD) in 2016. Digestive Diseases and Sciences, 61, 1356-1364. https://doi.org/10.1007/s10620-016-4079-4

[11] Singh, D., Das, C. and Baruah, M. (2013) Imaging of Nonalcoholic Fatty Liver Disease: A Road Less Travelled. Indian Journal of Endocrinology and Metabolism, 17, 990-995. https://doi.org/10.4103/2230-8210.122606

[12] Paparo, F., Corradi, F., Luca, C., Matteo, R., Andrea, M., Lucio, M., Giovanni, C., Giovanni, C. and Gian, A.R. (2014) Real-Time Elastography in the Assessment of Liver Fibrosis: A Review of Qualitative and Semi-Quantitative Methods for Elastogram Analysis. Ultrasound in Medicine and Biology, 40, 1923-1933. https://doi.org/10.1016/j.ultrasmedbio.2014.03.021

[13] Boursier, J. and Cales, P. (2010) Clinical Interpretation of Fibroscan ${ }^{\circledast}$ Results: A Real Challenge. Liver International, 30, 1400-1402.

https://doi.org/10.1111/j.1478-3231.2010.02355.x

[14] de Ledinghen, V., Wong, V.W., Vergniol, J., et al. (2012) Diagnosis of Liver Fibrosis and Cirrhosis Using Liver Stiffness Measurement: Comparison between M and XL Probe of FibroScan ${ }^{\oplus}$. Journal of Hepatology, 56, 833-839. https://doi.org/10.1016/j.jhep.2011.10.017

[15] Freedman, D.S., Horlick, M. and Berenson, G.S. (2013) A Comparison of the Slaughter Skinfold-Thickness Equations and BMI in Predicting Body Fatness and Cardiovascular Disease Risk Factor Levels in Children. American Journal of Clinical Nutrition, 98, 1417-1424. https://doi.org/10.3945/ajcn.113.065961

[16] Brunt, E.M., Wong, V.W., Nobili, V., Day, C.P., Sookoian, S., Maher, J.J., Bugianesi, 
E., Sirlin, C.B., Neuschwander-Tetri, B.A. and Rinella, M.E. (2015) Nonalcoholic Fatty Liver Disease. Nature Reviews Disease Primers, 1, Article No. 15080. https://doi.org/10.1038/nrdp.2015.80

[17] Ezzat, M.W., Ragab, S., Ismael, N.A., Abd El Baky, A.M., Farouk, H. and Abdel Rasheed, I.A. (2012) Frequency of Non-Alcoholic Fatty Liver Disease in Overweight/Obese Children and Adults: Clinical, Sonographic Picture and Biochemical Assessment. Journal of Genetic Engineering and Biotechnology, 10, 221-227. https://doi.org/10.1016/j.jgeb.2012.05.006

[18] Rafiq, N., Bai, C., Fang, Y., Srishord, M., McCullough, A., Gramlich, T. and Younossi, Z.M. (2009) Long-Term Follow-Up of Patients with Nonalcoholic Fatty Liver. APRICOT Clinical Investigators. Clinical Gastroenterology and Hepatology, 7, 234-238. https://doi.org/10.1016/j.cgh.2008.11.005

[19] Mustapic, S., Ziga, S., Matic, V., Bokun, T., Radic, B., Lucijanic, M., Marusic, S., Babic, Z. and Grgurevic, I. (2018) Ultrasound Grade of Liver Steatosis Is Independently Associated with the Risk of Metabolic Syndrome. Canadian Journal of Gastroenterology and Hepatology, 2018, Article ID: 8490242. https://doi.org/10.1155/2018/8490242

[20] McPherson, S., Hardy, T., Dufour, J.F., Petta, S., Romero-Gomez, M., Allison, M., Oliveira, C.P., Francque, S., Van Gaal, L., Schattenberg, J.M., Tiniakos, D., Burt, A., Bugianesi, E., Ratziu, V., Day, C.P. and Anstee, Q.M. (2017) Age as Confounding Factor for the Accurate Non-Invasive Diagnosis of Advanced NAFLD Fibrosis. American Journal of Gastroenterology, 112, 740-751. https://doi.org/10.1038/ajg.2016.453

[21] Rashed, H., Eltibi, D., Eissa, A. and Kassas, M. (2019) Assessment of Liver Fibrosis Using Real Time Elastography and FIB 4 Score in Comparison to Liver Biopsy in Chronic HCV Egyptian Patients. The Egyptian Journal of Hospital Medicine, 74, 1836-1843.

[22] Ochi, H., Hirooka, M., Koizumi, Y., Miyake, T., Tokumoto, Y., Soga, Y., Tada, F., Abe, M., Hiasa, Y. and Onji, M. (2012) Real-Time Tissue Elastography for Evaluation of Hepatic Fibrosis and Portal Hypertension in Non Alcoholic Fatty Liver Diseases. Hepatology, 56, 1271-1278. https://doi.org/10.1002/hep.25756

[23] Kanamoto, M., Shimada, M., Ikegami, T., Uchiyama, H., Satoru Imura, S., Morine, Y., Kanemura, H., Yusuke, A.Y. and Nii, A. (2009) Real Time Elastography for Noninvasive Diagnosis of Liver Fibrosis. Journal of Hepato-Biliary-Pancreatic Sciences, 16, 463-467. https://doi.org/10.1007/s00534-009-0075-9

[24] Hashemi, S., Alavian, S.M. and Gholami-Fesharaki, M. (2016) Assessment of Transient Elastography (FibroScan) for Diagnosis of Fibrosis in Non-Alcoholic Fatty Liver Disease: A Systematic Review and Meta-Analysis. Caspian Journal of Internal Medicine, 7, 242-252.

[25] Di, N., Zhou, X., Chen, Y., Zhao, X., Li, L., Jiang, L., Luo, B., Chen, X. and Yang, D. (2019) Could Semiquantitative Analysis of Real-Time Ultrasound Elastography Distinguish More Liver Parenchyma Alterations of Nonalcoholic Fatty Liver Disease in Patients with Polycystic Ovary Syndrome. Archives of Endocrinology and Metabolism, 63, 128-136. https://doi.org/10.20945/2359-3997000000119 


\section{Abbreviations}

RTE: Real-time elastography

NAFLD: Non alcoholic liver disease

PPV: Positive predictive value

NPV: Negative predictive value

AUC: Area under the Curve

NFS: NAFLD fibrosis score 